\title{
The human factor in an effective structure management system
}

\author{
S. Hand \\ Tralee, Co. Kerry, Ireland \\ L. Caldwell \\ NRCS (retired), Stillwater, Oklahoma, USA \\ J. Scannell \\ USEngineering Solutions Corp., Hartford, Connecticut, USA
}

\begin{abstract}
This paper demonstrates that while an effective structure monitoring system benefits strongly from the integration of modern technologies, human experience and oversight remain the essential component. The myriad of technologies available for structure monitoring and management are improving at a great rate. These technologies provide analysis and oversight at levels which historically have been uneconomical or unachievable. A single instance of the DamWatch application is providing real-time, always-on monitoring of 12,000 dam structures for 3,000 users in the United States (Caldwell, Scannell, \& Herbert, 2014). Automated systems can tirelessly monitor data feeds, rapidly perform complex calculations and dispatch notifications. However, this paper argues that the impacts of this growing role for technology, while powerful, is still superseded by the impacts of the human input in structure management systems. An optimal structure management system should be designed with this in mind. This includes ensuring data is complete and accurate, easily accessible and understandable for users. User contribution and involvement in structure management systems should not be limited by an individual's computer literacy. Users should be trained and supported to ensure they are able to react to and leverage data provided by information systems. Clearly defined protocols allow individuals to make informed decisions and organizations to respond promptly to developing situations. To assess these arguments we will examine a number of case studies. These case studies will focus on hydrologic events which affected bridge and dam structures in the care of multiple, unrelated managing authorities. By exploring the incidents, the responses and the eventual outcomes, we will weigh the role of human data in the effective management of structures exposed to the natural environment.
\end{abstract}

\section{INTRODUCTION}

Technology is becoming an integral part of routine and emergency management of bridges and dams. Remote instrumentation and structure management systems are providing data and insight that has previously been unfeasible. Automated systems can tirelessly monitor data feeds, rapidly perform complex calculations and dispatch notifications on thousands of structures simultaneously. As these technologies continue to develop and assimilate into the process of structure management, the question of whether they are being designed and integrated effectively should be asked. The human factor remains core to the effectiveness of a structure monitoring system, regardless of the sophistication of technology employed in the system. This paper examines the experiences of another high-risk industry, nuclear power plants, which have experienced and addressed many of the human factor issues which may begin to affect bridge and dam safety groups as they incorporate advanced structure management systems into their processes.

\subsection{BridgeWatch and DamWatch}

USEngineering Solutions Corporation (USES) is a developer of software solutions that enable critical infrastructure owners, regulators, and asset managers to monitor, in real-time, their bridge, dam, levee, and other hydrologic infrastructure. BridgeWatch and DamWatch are the two USES software applications of particular relevance to this paper. They are patented web-based systems which allows operators, general staff, emergency managers, and state safety personnel to store and retrieve data, monitor storm and seismic events, and quickly respond to potentially destructive events.

The BridgeWatch and DamWatch systems gather real-time meteorological and hydrological data from sources such as the National Oceanic and Atmospheric Administration (NOAA), National Weather Service (NWS), United States Geological Survey (USGS), and the NRCS Snow Telemetry (SNOTEL) system. They then compare meteorological data against established site-specific thresholds and alerts predetermined staff of anticipated spillway flows. Users are automatically alerted by cell phone texts 
and emails. Upon notification, staff are dispatched as needed during or after an event to specific structures for which alerts were issued. The system also provides detailed ticketing and dynamic forms to allow users to record information on the condition of structures and initiate follow-up actions.

BridgeWatch and DamWatch systems store thousands of files of site-specific data such as as-built drawings, design data, O\&M inspection reports, emergency action plans, breach inundation maps, plans of action, photos, and videos. Remote access to this data enables users to interact with on-site personnel and specialists in various offices. The system also features simulated alert notifications that can be used to perform realistic tabletop exercises with dam owners, first responders, and other users (Caldwell, et al., 2014).

\subsection{USDA NRCS}

USDA's Natural Resources Conservation Service (NRCS) has partnered with USEngineering Solutions Corporation (USES) to implement their Webbased application DamWatch to monitor and store data for dams constructed with USDA assistance. Since 1948, USDA-NRCS has assisted project sponsors with construction of 11,900 dams in 47 states and Puerto Rico (Durgin, 2014), with financial and technical assistance from one of the following USDA Watershed Program authorizations: Public Law 78-534 (78th U.S. Congress (2nd session), 1944), Public Law 83-566 (83rd U.S. Congress (2nd session), 1987), Pilot Watershed Program (83rd U.S. Congress (1st session), 1953), or the Resource Conservation and Development (RC\&D) Program (87th U.S. Congress (2nd session), 1962). Watershed dams are located in all states except Alaska, Delaware, and Rhode Island.

These watershed dams are federally assisted, but not owned by the Federal Government. They are locally owned and maintained by project sponsors. Sponsors are generally local conservation districts, special-use conservancy districts, or municipalities; and usually have easements on private lands to construct, operate, and maintain the watershed dams. In most cases, sponsors have nontechnical personnel in charge of the operation and maintenance of the dams, and most of the project sponsors rely on NRCS for technical assistance.

Typically, watershed dams are earthen embankments ranging from 20 to 80 feet in height with earthen vegetated spillways and concrete or metal principal spillways (USDA NRCS, 2014). Many are located in remote areas. Most of the dams are designed primarily for flood control, grade stabilization, water supply, or recreation. Therefore, they typically do not store much water except for short periods following large storm events (Caldwell, et al., 2014).

\section{HUMAN FACTORS IN THE NUCLEAR INDUSTRY}

The contribution of human factors to adverse events has received considerable attention in high-risk industries such as aerospace, medical, nuclear and petroleum industries. The nuclear industry in particular can provide insights for the bridge and dam safety industry. Due in part to the nature of their work, the nuclear industry has long incorporated technology as part of their management and safety procedures. The lessons learned by the nuclear industry over the past 30 years can help other industries as they incorporate technology into their routine procedures. The ThreeMile Island incident on March 28, 1979 was a catalyst for human reliability analysis (HRA), as observed by E. Hollnagel based on a notable increase in the number of HRA methods (Figure 1) (Hollnagel, 2005).

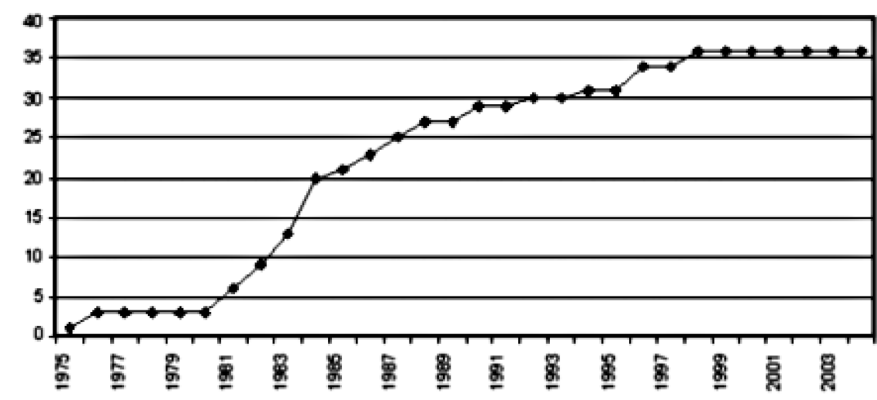

Figure 1. Cumulated number of HRA methods according to year of publication (Hollnagel, 2005).

Separately the author notes two trends in the 40 years leading up to 2005: "a decrease in the number of accidents attributed to technological failures, among other things due to an actual increase in the reliability of technological systems". And, at least partially related: "an increase in the number of accidents attributed to human performance failures".

Similarly, a 2004 report by the Nuclear Energy Agency noted that $48 \%$ of events reported at nuclear installations could be attributed to failure in human actions, and this figure has increased with time. In the 1980 s approximately $45 \%$ of events could be attributed to failure in human actions, a figure which had increased to $55 \%$ by the 1990s (Committee on Nuclear Regulatory Activities (OECD NEA), 2004). This has led to an increased focus on considering human reliability as a core aspect of system design. Human factors are explicitly cited in International Atomic Energy Agency (IAEA) guidance (Office of Nuclear Regulation, 2014): "Systematic consideration of human factors, including the human-machine interface shall be included at an early stage in the design process for a nuclear power plant and shall continue throughout the entire process..." (International Atomic Energy Agency, 2012) and "Verification and validation of aspects of human factors shall be included at appropriate stages 
to confirm that the design adequately accommodates all necessary operator actions." (International Atomic Energy Agency, 2010) amongst other examples.

Research in the area of human factors and reliability has identified a range of factors which should be considered in the design and operation of large systems. For this paper we have selected a few factors we feel are of particular relevance to the bridge and dam safety industry at this point in time.

\section{HUMAN FACTORS IN BRIDGE AND DAM MANAGEMENT SYSTEMS}

\subsection{Organizational decisions}

When initiating considerable technology changes to practices in an organization, it is important to include personnel in the process. Organizational decisions are a significant human factor which can negate other human factors such as training and interface design. In analyzing a number of nuclear installation event case studies, it was noted that most regulators failed to put sufficient emphasis on "management and organizational capability to handle the interaction between technology, economics, human factors and safety in a changing environment" and that, in the past, regulators did not pay as much attention to "the impact of organizational changes on safety as they have on technical plant modifications" (Manna, 2007).

An important organizational decision is to involve general users in the early stages of the adoption of a new structure management system. If this poorly handled there is a risk of apathy amongst personnel who do not feel informed or involved in the adoption of the new system, and in the worst case scenario lead to a refusal to adopt the changes. This will considerably diminish the value of introducing a new structure management system into the processes of an organization, and may prohibit any natural development of the system's role in the organization. Personnel can be engaged by involving key representatives at consultation stages, providing training and inviting feedback and input on the structure management system's role in the organization.

One contributor to our research noted that in his organization, which oversees a large number of bridges and dams, the majority of personnel are not engineers. There is limited interest in the work of bridge and dam management as it can be seen as complex and intimidating. Offering tools which provide clear information and action steps would involve personnel and increase awareness of bridge and dam safety issues.

\subsection{The human data source}

There are significant benefits to involving general staff and even local interest groups in the structure management processes. The human data source can considerably extend the impact and reach of structure management systems. Individuals who are offered the tools to provide their input on issues at local structures can acts as "eyes on the ground". The effort of maintaining a minimum oversight on a large, distributed network can be shared amongst a far larger number of individuals, who may be interacting with or in the vicinity of the structures on a regular basis in an unrelated capacity. However if their observations can be collected at regular intervals it will provide another, extremely valuable, data source for early-warning of issues developing at structures. With well-designed prompts individuals of all levels can provide information on the condition of a structure which are difficult if not impossible to measure using instrumentation.

Furthermore, during emergency events, general staff and local interest groups involved in structure management systems can provide an accurate first assessment to confirm or dispute the information provided by monitoring technologies. They can also provide general information on the current condition of local structures. This is extremely useful to structure management authorities as it reduces reaction time, multiple structures are receiving a screening stage assessment simultaneously. This can ensure the inspection and maintenance team are directed to the structures requiring their specialist skills in a prompt manner. Thus an organization's limited high-skilled resources are used efficiently at the time they are most needed, and they are not exhausted or frustrated inspecting structures which are coping with the conditions or which have received false alerts.

\subsection{Design of procedures}

It is important that the actions to be carried out in an emergency have been agreed upon, clearly outlined and made readily available to the responsible people to ensure they can respond promptly and confidently during an emergency. High-risk industries have long placed a great influence on the existence and adherence to procedures. Procedures provide objective guidance to personnel throughout all stages of operation and provide a common expectation. Without pre-planned procedures, operators would have to make important decisions with little time for detailed consideration during emergencies. They also reduce the mental burden placed on personnel during critical situations. Thus they are correctly considered an integral part of the management of large assets such as bridges and dams. However, as discussed by Yves Dien (Dien, 1998), rigid design and an over-reliance on procedures can create critical voids. 
Yves Dien published a study examining 100 fullscale simulations carried out by Electricite de France (EDF) to examine how control room operators coped with emergency situations. The study found that operators do deviate from the exact procedures outlined. These incidents of deviation were rare, and in the cases simulated they were of little consequence, but are noteworthy for a number of reasons. The deviations typically occurred due to procedures not strictly matching the situation. This misalignment highlights the crucial role of the human factor in the effective implementation of a management system.

Operations personnel will occasionally encounter situations not explicitly covered by procedures, and will have to make decisions about how to adapt existing procedures to address the current issue or use their own knowledge to address it. More frequently personnel will encounter obstacles to their progress; equipment failures, communication and power outages, unavailability of personnel, which they must circumvent to complete the procedures. Finally, the procedures themselves implicitly require a minimum level of knowledge of the individual carrying out the procedures. The minimum level of knowledge can affect the complexity of the procedure: a single step may need to detail all actions required to carry out the step, or if employees are knowledgeable the step could simply state the outcome required. As an example, "close the door" assumes a certain amount of the operator, whereas outlining each step required to assess whether a door requires closing, how it should be closed, and whether it has been closed may be frustrating for the knowledgeable operator. Such a detailed outline increases the complexity and timedemand of tasks.

A study by $\mathrm{Xu}$ et al on computerized emergency operating procedures found that an individual's training level had a significant effect on the "error rate, operation time and subjective workload of EOP operation" (Xu, et al., 2008). Educating staff not only in the implementation of prescribed procedures, but also the reasoning behind the steps in those procedures and the intended outcome will greatly enhance the ability of a system to cope with routine issues and emergencies. Staff would also benefit from education on the nature of the issues in their industry in general, as a deeper understanding of the phenomena will allow a more informed response during emergency situations which deviate from theoretical procedures.

\subsection{Interface}

An important aspect of bridge and dam management is the implementation of emergency action plans (EAP) or plans of action (POA) during events. The vigilance of an early-warning system, and the insight of monitoring equipment are of great value in notifying personnel of the need to implement an EAP or
POA. However, the system must provide the key information in an easy to digest manner to ensure users will take the appropriate action in accordance with procedures. Interface design has been identified as an important factor in ensuring nuclear plant operators interpret and use emergency operating procedures effectively (Xu, et al., 2008). EAPs at many bridge and dam authorities remain generally paperbased as their usage pre-dates computer technology or they have not been converted to an electronic file. Nuclear operators have been quick to adopt computer-based documentation as computer systems are an integral part of the day-to-day operations of nuclear power plants. Bridge and dam managers have begun the switch to electronic storage of documentation as computer usage and aptitude has become prevalent in general society.

As digitized emergency action plans or plans of action become part of bridge and dam management processes, it is important that the impact of interface design is given serious consideration. Computer interfaces provide many more presentation options than the constrained format of paper-based documents. However simply digitizing a hard copy of procedures provides limited gains, and has been found to be inferior to having a graphical presentation (Niwa, et al., 1996). To truly be beneficial, it is important that computerized procedures are presented such that the operator can consult and understand them without adding additional mental burden during emergency situations. The prompts should also be designed such that subjectivity and the potential for mistakes or oversights are minimized. In examining operator interaction with emergency operations procedures during simulations $\mathrm{Xu}$ et al (Xu, et al., 2008) found both task complexity and presentation style were significant factors in the error rates for skilled operators. Events in the bridge and dam industry may not be quite as time-critical as those in the nuclear industry, yet clear, understandable procedures are key to an effective response whether it is measured in seconds, minutes, hours or days.

\subsection{Training}

A further observation by $\mathrm{Xu}$ et al based on their study was that "training level can significantly influence error rate, operation time and subjective workload of EOP operation." (Xu, et al., 2008). It is vital to provide users with initial training, and ideally ongoing refresher sessions, to gain the maximum benefit from the adoption of a structure management system. To confidently integrate the system into their routine and emergency processes, users need to understand the system's intended role and how to interact with the software. This enables the user to incorporate usage of the structure management system into their regular schedule in order to increase their productivity and the impact of their daily work. Fur- 
thermore, it allows the user to confidently use the software in emergency situations while under considerable stress and where rapid response times can be crucial.

There are also tangential benefits of training sessions which allow users to interact with the structure management system. It has been the experience of both USEngineering Solutions and NRCS that training sessions have provided opportunities for users to suggest additional applications for the BridgeWatch and DamWatch system within their organization, based on the user's personal experience working in the field. Training sessions also offer the opportunity to run simulations such as table top exercises, where issues in the process chain can be identified before they occur during a real event.

\subsection{Digital library}

The opportunity to digitize large volumes of documentation has been found to provide significant improvements in the informed decision making of operations staff. As a pilot project for the NRCS's national DamWatch system, DamWatch system was implemented for the state of Oklahoma. This DamWatch system was populated with over 30,000 files by NRCS Oklahoma staff, including as-built drawings, emergency action plans and inspection reports. The NRCS offices in Oklahoma have observed a shift in behavior where personnel now consult DamWatch first when seeking documentation related to particular dams. A web-based, structure-centric management system removes issues with locating documents, loss or damage to documents, access outside of opening hours. This removes significant obstacles to information access, and encourages personnel to retrieve all available information when making operation decisions. Having EAPs accessible on the web also helps assure that users have access to the latest version of the document instead of having to rely on each holder updating sections of the document.

\section{CASE STUDY: FLOODING IN SOUTH CAROLINA}

\subsection{Event summary}

In October 2015 a significant precipitation event affected South Carolina in the United States. Recordbreaking amounts of rain were recorded, with storm total rainfall amounts of 15-25 inches recorded in a number of areas and isolated maximum amounts in excess of 25 inches recorded over a period of approximately 120 hours (National Weather Service, Charleston, SC Weather Forecast Office, 2016).

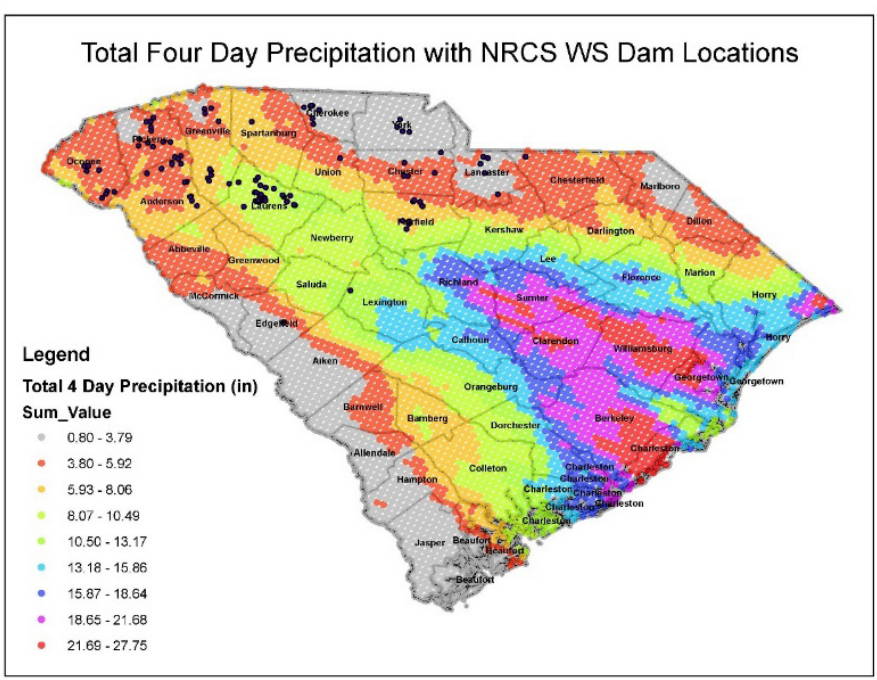

Figure 2. Storm total rainfall with NRCS watershed dam locations (Durgin \& Caldwell, 2015).

This event caused extensive damage, including the loss of 19 lives (Kirby, 2015) and the failure of 36 dams (National Performance of Dams Program, 2016).

The USDA National Resource Conservation Service has 105 watershed dams in South Carolina, distributed mainly in the northern and north western corners of the state, as can be seen in Figure 2. This area did not experience the levels of precipitation reported in Columbia and Charlestown areas, but the watersheds of the NRCS dams did experience rainfall amounts ranging from 2.8 to 8.9 inches (Durgin \& Caldwell, 2015).

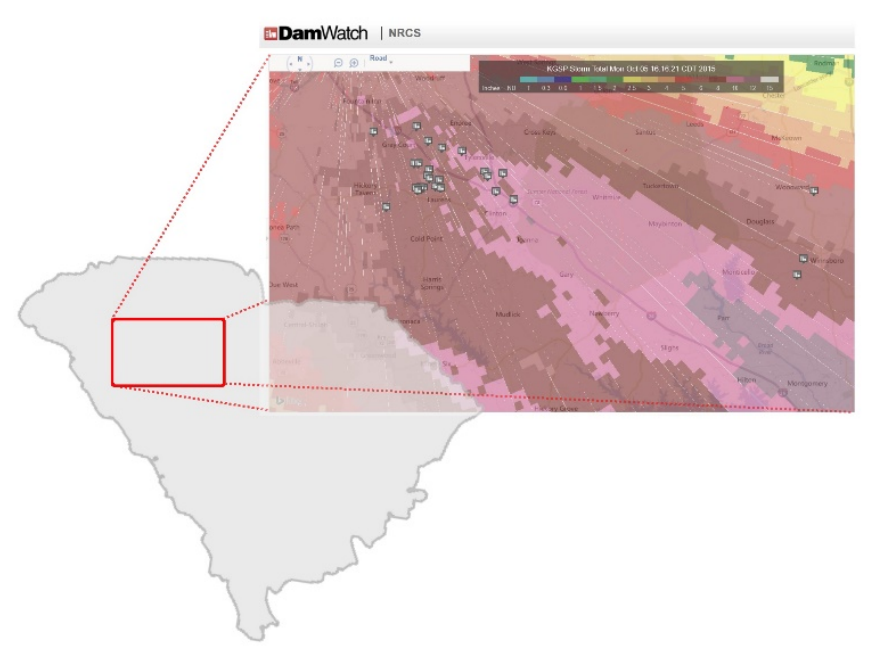

Figure 3. Location of alert notification dispatched by DamWatch for NRCS dams.

On October $4^{\text {th }} 2015$, DamWatch issued 29 alert notifications for structures in South Carolina (Figure 3). The National Weather Service's NEXRAD service uses radar to produce precipitation data products. This data can be acquired as a gridded shapefile, with each cell representing the amount of precipitation in inches detected by a radar station over the corresponding geographic area. DamWatch continually polls and 
process this NEXRAD data in order to assess the amount of precipitation impacting on each monitored dam's defined drainage basin. If the precipitation levels reported by NEXRAD exceed a dam's defined thresholds an alert notification is issued. The NRCS uses a two stage warning protocol for DamWatch notifications. The first warning level is a rainfall alert. A rainfall alert is defined as the amount of rain deemed sufficient to fill the impounded reservoir from its normal pool level. A spillway flow alert is the second, more serious, warning level. It is issued when a precipitation volume is deemed to have had potential to bring the impounded reservoir from a normal pool level to active flow on the auxiliary spillway.

The 29 alert notifications issued by DamWatch were comprised of 11 rainfall alerts and 18 spillway flow alerts (Table 1).

Table 1. DamWatch notifications issued on 4th October 2015 in South Carolina.

\begin{tabular}{rcc}
\hline & $\begin{array}{c}\text { Rainfall } \\
\text { Tlert }\end{array}$ & $\begin{array}{c}\text { Spillway Flow } \\
\text { Alert }\end{array}$ \\
\cline { 2 - 3 } Total & 11 & 18 \\
Sow hazard dam & 6 & 16 \\
Significant hazard dam & 3 & 2 \\
High hazard dam & 2 & 0 \\
Spillway was flowing & 2 & 16 \\
Continued to monitor & 2 & 11 \\
\hline
\end{tabular}

Field visits were carried out by NRCS personnel to close the alerts in DamWatch. Based on these field visits spillway flows were confirmed at 16 of the 18 dams which received spillway flow alerts. Eleven of these structures were given a "Monitor" status; the dams required at least one follow-up visit to monitor their condition post-event. Two of the eleven structures which received rainfall alerts were confirmed as having spillway flows. Both of these structures were given a "Monitor" status. All inspections bar one, due to inaccessibility, were carried out by October $6^{\text {th }} 2015$ (Durgin \& Caldwell, 2015).

\subsection{Learning points}

A number of the key lessons noted in the NRCS report on the South Carolina flooding of October 1-4 2015 (Durgin \& Caldwell, 2015) are worth noting as they are real-world experiences in line with aspects of the discussion in this paper.

\subsubsection{Screening stage}

The report noted that it would have been valuable to have local project sponsors carry out a first pass to improve the prioritization of field visits. This would require some training and the creation of a protocol on the exact assessments these individuals should make, but there would be great benefits in dispatch- ing inspection and maintenance teams more effectively.

\subsubsection{Training}

During the event personnel responded well to the flooding but were under pressure to act quickly. This was the first experience of using DamWatch intensively for a large portion of personnel and they did not feel as comfortable using the software as they would have liked. There was a general consensus that further training in the use of DamWatch would be beneficial in ensuring it is used effectively.

\subsubsection{Access to information}

Issues were encountered during the response to the South Carolina event when information on dam was not available on DamWatch or users had difficulty retrieving the information. This highlighted a need at an organizational level to continue the work which was carried out in the pilot implementation of DamWatch in Oklahoma. All documents available for NRCS dams would be of even greater value if it is digitized and made readily available to personnel via DamWatch. Further training will increase the ability of users to confidently retrieve all available information from DamWatch.

\section{CONCLUSIONS}

It is clear that human interaction with and as part of a structure management system is crucial to the system's effectiveness. These lessons have been learnt in many high-risk industries, and are already being experienced by NRCS and other BridgeWatch and DamWatch clients as structure management systems become an integral part of routine and emergency processes. As part of the design stage and as an ongoing concern the human factor must be accounted for if a structure management system is to reach its full potential.

\section{REFERENCES}

78th U.S. Congress (2nd session), 1944. Pick-Sloan Flood Control Act of 1944 (P.L. 78-534). Washington D.C.(Columbia): U.S. Congress.

83rd U.S. Congress (1st session), 1953. Public Law 83-156 An Act making appropriations for the Department of Agriculture for the fiscal year ending June 30, 1954, and for other purposes. Washington D.C.: U.S. Congress.

83rd U.S. Congress (2nd session), 1987. Thw Watershed Protection and Flood Prevention Act (P.L. 83-566). Washington D.C.: U.S. Congress.

87th U.S. Congress (2nd session), 1962. Public Law 87 - 703, H.R. 12391, Food and Agriculture Act of 1962. Washington D.C.: U.S. Congress.

Caldwell, L. W., Scannell, J. P. \& Herbert, N., 2014. Improving public safety by using DamWatch to monitor 11,900 USDA-assisted dams. Perth, Australia, CRC Press, pp. 575-583. 
Committee on Nuclear Regulatory Activities (OECD NEA), 2004. Nuclear regulatory challenges related to human performance, Paris: Nuclear Energy Agency.

Dien, Y., 1998. Safety and application of procedures, or 'how do 'they' have to use operating procedures innuclear power plants?. Safety Science, pp. 179-187.

Durgin, S., 2014. Natural Resources Conservation Service Engineering and Dam Safety Resources.

Emmitsburg(Maryland): Association of State Dam Safety Officials.

Durgin, S. \& Caldwell, L., 2015. NRCS Experience Using DamWatch ${ }^{\circledR}$ during October 1-4, 2015 Storms in South Carolina, Washington D.C.: USDA National Resource Conservation Service.

Hollnagel, E., 2005. Human reliability assessment in context. Nuclear Engineering and Technology, pp. 159-166.

International Atomic Energy Agency, 2001. A systematic approach to human performance improvement in nuclear power plants: Training solutions, Vienna: International Atomic Energy Agency.

International Atomic Energy Agency, 2010. Specific Safety Guide: Deterministic Safety Analysis of Nuclear Power Plants, Vienna: International Atomic Energy Agency.

International Atomic Energy Agency, 2012. Specific Safety Requirements: Safety of Nuclear Power Plants: Design (No. SS-2/1), Vienna: International Atomic Energy Agency.

Johnson, C. W., 2006. Why did that happen? Exploring the proliferation of barely usable software in healthcare systems. Quality and Safety in Healthcare, 1(15), p. December.

Kirby, J., 2015. Dams Fail Across South Carolina As Floodwaters Kill 19, New York: New York Magazine.

Manna, G., 2007. Human and organizational factors in nuclear installations: analysis of available models and identification of $R \& D$ issues., Luxembourg: JRC - European Commission.

National Performance of Dams Program, 2016. October 2015 South Carolina Dam Failures. [Online]

Available

at: http://npdp.stanford.edu/2015_SC_Flood_Failures

National Weather Service Charleston, SC, 2016. Map of Storm Total Rainfall. [Online]

Available

at: http://www.weather.gov/images/chs/events/HistoricFloodin g_Oct2015/StormTotalRainfall.png

National Weather Service, Charleston, SC Weather Forecast Office, 2016. Historic Flooding - October 1-5, 2015. [Online]

Available at: http://www.weather.gov/chs/HistoricFloodingOct2015

Niwa, Y., Hollnagel, E. \& Green, M., 1996. Guidelines for the presentation of emergency operating procedures using advanced information technology. Nuclear Engineering and Design, Volume 167 (2), pp. 113-127.

Office of Nuclear Regulation, 2014. Human factors Integration. s.1.:Health and Safety Executive.

USDA NRCS, 2014. NRCS Inventory of Dams, s.1.: United States Department of Agriculture National Resource Conservation Service.

Wang, X. et al., 2010. An Interactive Visual Analytics System for Bridge Management. Computer Graphics Forum, 29(3), pp. 1033-1042.

$\mathrm{Xu}$, S. et al., 2008. An ergonomics study of computerized emergency operating procedures: Presentation style, task complexity, and training level.. Reliability Engineering and System Safety 93.10, pp. 1500-1511. 